\title{
Leaf-litter breakdown in tropical streams: is variability the norm?
}

\author{
Luz Boyero ${ }^{1,2,3,25}$, Richard G. Pearson ${ }^{3,26}$, Mark 0. Gessner ${ }^{4,5,6,7,27}$, David Dudgeon ${ }^{8,28}$, \\ Alonso Ramírez ${ }^{9,29}$, Catherine M. Yule $e^{10,30}$, Marcos Callisto ${ }^{11,31}$, Catherine M. Pringle ${ }^{12,32}$, \\ Andrea C. Encalada 13,14,33, Muthukumarasamy Arunachalam 15,34, Jude Mathooko 16,35, \\ Julie E. Helson ${ }^{17,36}$, José Rincón ${ }^{18,37}$, Andreas Bruder ${ }^{6,7,19,38}$, Aydeé Cornejo ${ }^{20,39}$, \\ Alexander S. Flecker ${ }^{21,40}$, Catherine Mathuriau ${ }^{22,41}$, Charles M'Erimba $^{16,42}$, \\ José F. Gonçalves $\mathrm{Jr}^{11,23,43}$, Marcelo Moretti ${ }^{11,24,44}$, and Tajang Jinggut ${ }^{10,45}$ \\ ${ }^{1}$ Faculty of Science and Technology, University of the Basque Country (UPV/EHU), Leioa, Spain \\ ${ }^{2}$ IKERBASQUE, Basque Foundation for Science, Bilbao, Spain \\ ${ }^{3}$ School of Marine and Tropical Biology, and TropWATER, James Cook University, Townsville, Queensland 4811 Australia \\ ${ }^{4}$ Department of Experimental Limnology, Leibniz Institute of Freshwater Ecology and Inland Fisheries (IGB), Alte Fischerhütte 2, \\ 16775 Stechlin, Germany \\ ${ }^{5}$ Department of Ecology, Berlin Institute of Technology (TU Berlin), Ernst-Reuter-Platz 1, 10587 Berlin, Germany \\ ${ }^{6}$ Department of Aquatic Ecology, Eawag: Swiss Federal Institute of Aquatic Science and Technology, Überlandstrasse 133, 8600 \\ Dübendorf, Switzerland \\ ${ }^{7}$ Institute of Integrative Biology (IBZ), ETH Zurich, Zurich, Switzerland \\ ${ }^{8}$ School of Biological Sciences, The University of Hong Kong, Hong Kong SAR, China \\ ${ }^{9}$ Department of Environmental Science, University of Puerto Rico, P.O. Box 70377, San Juan, Puerto Rico 00936 USA \\ ${ }^{10}$ School of Science, Monash University, Jalan Lagoon Selatan, Bandar Sunway, 46150 Selangor, Malaysia \\ ${ }^{11}$ Laboratorio de Ecologia de Bentos, Instituto de Ciencias Biológicas, Universidade Federal de Minas Gerais, CP 486, 30161-970 \\ Belo Horizonte, Minas Gerais, Brazil \\ ${ }^{12}$ Odum School of Ecology, University of Georgia, Athens, Georgia 30602-2602 USA \\ ${ }^{13}$ Laboratorio de Ecología Acuática, Colegio de Ciencias Biológicas y Ambientales, Universidad San Francisco de Quito, Campus \\ Cumbayá, P.O. Box 171200 841, Quito, Ecuador \\ ${ }^{14}$ IMAR-CMA and Department Life Sciences, University of Coimbra, 3001401 Coimbra, Portugal \\ ${ }^{15}$ Sri Paramakalyani Centre for Environmental Sciences, Manonmaniam Sundaranar University, Alwarkurichi, Tamil Nadu, India \\ ${ }^{16}$ Department of Biological Sciences, Egerton University, P.O. Box 536, Egerton, Kenya \\ ${ }^{17}$ Surface and Groundwater Ecology Research Group, Department of Biological Sciences, University of Toronto at Scarborough, \\ 1265 Military Trail, Toronto, Ontario M1C 1A4 Canada \\ ${ }^{18}$ Departamento de Biología, Facultad Experimental de Ciencias, Bloque A-2, Apartado 526, Universidad del Zulia, Maracaibo, \\ Venezuela \\ ${ }^{19}$ Department of Zoology, University of Otago, P.O. Box 56, 9054 Dunedin, New Zealand \\ ${ }^{20}$ Colección de Entomología, Instituto Conmemorativo Gorgas de Estudios de la Salud, Avenida Justo Arosemena and Calle 35, \\ 0816-02593, Panama City, Panama \\ ${ }^{21}$ Department of Ecology and Evolutionary Biology, Cornell University, Ithaca, New York 14853 USA \\ ${ }^{22}$ Centro de Investigaciones en Ecosistemas, Antigua Carretera a Pátzcuaro No. 8701, Ex-Hacienda de San José de la Huerta, CP \\ 58190, Morelia, Michoacán, Mexico \\ ${ }^{23}$ Laboratório de Limnología, Departamento de Ecología, IB, Universidade de Brasília,70910-900, Brasília, Federal District, Brazil \\ ${ }^{24}$ Laboratório de Ecologia de Insetos Aquáticos, Universidade Vila Velha, 29.102-920, Vila Velha, Espírito Santo, Brazil
}

Abstract: Many forested headwater streams are heterotrophic ecosystems in which allochthonous inputs of plant litter are a major source of energy. Leaves of riparian vegetation entering the stream are broken down by a combination of biotic and abiotic processes and, in most temperate and boreal streams, provide food and habitat for

\footnotetext{
E-mail addresses: ${ }^{25}$ luz.boyero@ehu.es; ${ }^{26}$ richard.pearson@jcu.edu.au; ${ }^{27}$ gessner@igb-berlin.de; ${ }^{28}$ ddudgeon@hku.hk; ${ }^{29}$ aramirez@ramirezlab.net; ${ }^{30}$ catherine.yule@monash.edu; ${ }^{31}$ callistom@ufmg.br; ${ }^{32}$ cpringle@uga.edu; ${ }^{33}$ aencalada@usfq.edu.ec; ${ }^{34}$ arunacm@gmail.com; ${ }^{35}$ mathookoj@yahoo.com; 36 julie.helson@alum.utoronto.ca; ${ }^{37}$ jerincon@luz.edu.ve; ${ }^{38}$ andreas.bruder@otago.ac.nz; ${ }^{39}$ aydcornejo@gmail.com; ${ }^{40}$ asf3@cornell.edu; ${ }^{41}$ mathuriau @oikos.unam.mx; ${ }^{42}$ merimba2000@yahoo.com; ${ }^{43}$ jjunior@unb.br; ${ }^{44}$ marcelo.moretti@uvv.br; ${ }^{45}$ tjin3@student.monash.edu
} 
dense populations of detritivorous invertebrates. However, tropical streams in different parts of the world show substantial variability in the number and diversity of leaf-shredding detritivores (hereafter detritivores). We used data obtained with standardized methods from multiple streams in Africa, the Americas, Asia, and Australia to test the hypothesis that this variability would lead to differences in the relative role of detritivores and microorganisms in the breakdown process. We also tested the hypotheses that variability in litter breakdown rates changes with litter type (native litter mixtures vs nonnative alder [Alnus glutinosa]) and is higher across regions within than outside the tropics. We found that litter breakdown rates were highly variable across sites, with no consistent pattern within geographic areas, although litter consumption by detritivores was negligible at several sites, all in America. Geographic patterns of litter breakdown also varied between litter types, with higher breakdown rates for alder than for native litter in most but not all regions. When litter breakdown rates at the tropical sites were compared to previously reported values from temperate and boreal regions, we found that differences in variability between tropical and temperate sites were inconsistent, with great differences among studies. Further global-scale studies will be needed to assess the extent to which latitudinal changes in the diversity and composition of microbial and detritivore assemblages contribute to variability in litter breakdown rates.

Key words: decomposition, shredders, microorganisms, tropical streams, variability

Many forested headwater streams are heterotrophic ecosystems in which inputs of plant litter from the surrounding forest are a major source of energy (Webster and Benfield 1986, Tank et al. 2010). Detrital inputs generally exceed within-stream primary production (Webster et al. 2006) because light is limited by riparian shading (Hill et al. 1995, Julian et al. 2011). Leaf litter entering the stream is transformed by a combination of biotic and abiotic processes, including the leaching of soluble leaf constituents, physical fragmentation, decomposition by fungi and bacteria, and consumption primarily by leaf-shredding detritivorous invertebrates (Gessner et al. 1999, Tank et al. 2010). These invertebrates are a major link between terrestrial litter and the aquatic food web because they consume leaf litter and their feeding activity accelerates the production of fine particulate organic matter, which is the main food source of other detritivores, such as gatherer-collectors and filter-feeders (Cummins and Klug 1979).

These processes have been extensively described for temperate and boreal forested streams, which often have dense populations of leaf-shredding detritivores (hereafter detritivores) that significantly contribute to litter breakdown. In contrast, although some tropical streams around the world support abundant detritivores, many others do not (Boyero et al. 2009). Two decades ago, Irons et al. (1994) examined patterns of litter breakdown at 1 tropical, 1 temperate, and 1 boreal stream across a latitudinal gradient from Central America to Alaska, and suggested that leaf-shredding detritivores were scarcer and barely contributed to litter breakdown at the tropical site. Later reports of detritivore numbers in other tropical regions supported this observation (e.g., Dudgeon and Wu 1999, Dobson et al. 2002), whereas others did not (e.g., Cheshire et al. 2005, Camacho et al. 2009, Yule et al. 2009). Authors of a subsequent study across multiple sites on all continents concluded that the abundance and diversity of detritivores tended to increase with latitude (Boyero et al.
$2012 b)$ but that variability of detritivore numbers was higher within than outside the tropics (Boyero et al. 2011a).

To better elucidate this question, we explored the degree of variability in rates of litter breakdown across tropical streams by testing the following hypotheses: 1) the relative contribution of detritivores and microorganisms to litter breakdown varies greatly across tropical sites and geographic areas, 2) differences in breakdown of different litter types vary from site to site, and 3) variability in litter breakdown rates is higher across tropical sites than across sites outside the tropics. To this end, we first extended the data set of the previous global study (Boyero et al. 2011b) by complementing the data from a standard litter type (i.e., leaves of black alder, Alnus glutinosa (L.) Gaertn.) with unpublished breakdown rates from litter mixtures of 3 native species measured concurrently at 14 stream sites in Africa (1 site), Asia (3), Australia (1), Central America (3), the Caribbean (2), and South America (4). To assess rates of microbial and total breakdown, we measured mass loss of litter enclosed in fine- and coarse-mesh bags, respectively. Second, we compared variability in breakdown rates within this data set with that reported in 4 published large-scale studies in Europe.

\section{METHODS}

Fourteen study sites were established in the tropics (lat $23.5^{\circ} \mathrm{N}-23.5^{\circ} \mathrm{S}$ ) across the globe (Fig. 1, Table 1). At each site, we chose a single stream reach draining a forested watershed experiencing little human influence. Mean water temperature ranged from 15.4 to $26.0^{\circ} \mathrm{C}$, pH from 5.2 to 8.3 , and conductivity from 8 to $380 \mu \mathrm{S} / \mathrm{cm}$ (Table 1 ). We conducted the experiment at the season of maximum litter accumulation, which generally was the dry season. At each site, we collected freshly abscised leaves from 3 riparian tree species that were common native sources of litter in the study streams (42 species in total; Table S1), and we 

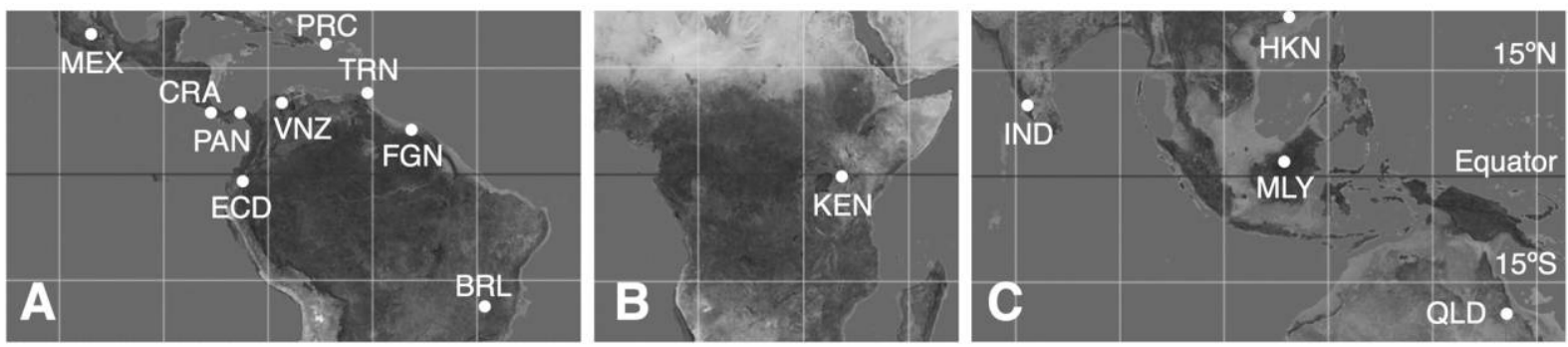

Figure 1. Map of the tropical zone (lat $23.5^{\circ} \mathrm{N}-23.5^{\circ} \mathrm{S}$ ) in America (A), Africa (B), and Asia and Australia (C) showing the locations of study sites. Site codes are given in Table 1.

used a $4^{\text {th }}$ tree species, black alder, as a reference in all sites (except in Venezuela). We used alder because it is very widespread and widely used in studies of litter breakdown in temperate and boreal streams of the northern hemisphere (e.g., Woodward et al. 2012) and because it is highly palatable to temperate and tropical detritivores (Graça et al. 2001).

We air-dried leaves, weighed them, and enclosed them in coarse-mesh $(10 \mathrm{~mm})$ and fine-mesh $(0.5 \mathrm{~mm})$ bags, which we placed in the streams. Each bag contained either alder leaves $(\sim 3 \mathrm{~g})$ or mixtures of leaves of the 3 native species $(\sim 1 \mathrm{~g} /$ species $)$. We retrieved 3 bags of each of these 4 types (coarse and fine mesh, alder and native litter) on each of 4 dates: initially before submergence of the litter in the streams to estimate mass loss caused by handling, and in most cases, after 2, 4, and $8 \mathrm{wk}$. We collected bags with a net $(0.5-\mathrm{mm}$ mesh) placed immediately downstream of the bag. We rinsed, oven-dried at 50 to $60^{\circ} \mathrm{C}$, and weighed leaves. At each site, we recorded the absolute latitude (degrees from equator), elevation ( $\mathrm{m}$ asl), water temperature $\left({ }^{\circ} \mathrm{C}\right), \mathrm{pH}$, and conductivity $(\mu \mathrm{S} / \mathrm{cm})$ to assess their influence, if any, on litter breakdown.

We estimated litter breakdown rate $(k)$ for each site and type of bag by linearly regressing $\ln$ (proportion of litter dry mass remaining) against thermal sums (degree days), rather than elapsed time in days, to normalize for the direct effect of temperature. Degree days were calculated as time (in $\mathrm{d}$ ) $\times$ the average stream temperature during the experiment, measured with submerged temperature data loggers with the threshold set at $0^{\circ} \mathrm{C}$ (Boyero et al. 2011b).

We first compared variability of $k$ values between litter types, separately for coarse- and fine-mesh bags, using the Levene's test of homogeneity of variances. We also compared variability of $k$ values between mesh types, separately for each litter type. We then compared variation in $\ln$ (proportion of litter dry mass remaining) between mesh sizes (coarse and fine), litter types (alder and native),

Table 1. Location of study sites, site codes, latitude, longitude, elevation, mean water temperature, $\mathrm{pH}$, and conductivity during the study. Temp. = temperature.

\begin{tabular}{|c|c|c|c|c|c|c|c|c|}
\hline Site & Code & Region & $\begin{array}{l}\text { Latitude } \\
\left({ }^{\circ}\right)\end{array}$ & $\begin{array}{l}\text { Longitude } \\
\qquad\left(^{\circ}\right)\end{array}$ & $\begin{array}{l}\text { Elevation } \\
(\mathrm{m} \text { asl })\end{array}$ & $\begin{array}{c}\text { Water temp. } \\
\left({ }^{\circ} \mathrm{C}\right)\end{array}$ & $\mathrm{pH}$ & $\begin{array}{l}\text { Conductivity } \\
(\mu \mathrm{S} / \mathrm{cm})\end{array}$ \\
\hline Brazil & BRL & Serra do Cipó & $19.27 \mathrm{~S}$ & $43.52 \mathrm{~W}$ & 1450 & 17.3 & 5.2 & 8 \\
\hline Costa Rica & CRA & La Selva Biological Station & $10.43 \mathrm{~N}$ & $84.03 \mathrm{~W}$ & 50 & 26.0 & 6.0 & 178 \\
\hline Ecuador & ECD & Tiputini Biodiversity Station & $0.74 \mathrm{~S}$ & $76.38 \mathrm{~W}$ & 263 & 24.3 & 7.1 & 70 \\
\hline French Guiana & FGN & Kourou & $5.07 \mathrm{~N}$ & $53.01 \mathrm{~W}$ & 100 & 24.4 & 6.8 & 19 \\
\hline Hong Kong & HKN & Tai Po Kau Forest & $22.43 \mathrm{~N}$ & $114.15 \mathrm{E}$ & 200 & 15.4 & 6.9 & 21 \\
\hline India & IND & Southwestern Ghats & $8.80 \mathrm{~N}$ & $77.32 \mathrm{E}$ & 380 & 18.0 & 7.5 & 20 \\
\hline Kenya & KEN & Nakuru & $0.37 \mathrm{~S}$ & $35.93 \mathrm{E}$ & 2307 & 16.5 & 8.3 & 136 \\
\hline Malaysia & MLY & Borneo & $3.15 \mathrm{~N}$ & $113.94 \mathrm{~W}$ & 283 & 23.7 & 8.3 & 275 \\
\hline Mexico & MEX & Michoacán & $19.73 \mathrm{~N}$ & $100.66 \mathrm{~W}$ & 2250 & 15.6 & 6.9 & 19 \\
\hline Panama & PAN & Soberanía National Park & $9.09 \mathrm{~N}$ & $79.44 \mathrm{~W}$ & 74 & 24.1 & 7.2 & 190 \\
\hline Puerto Rico & PRC & Luquillo Mountains & $18.32 \mathrm{~N}$ & $65.82 \mathrm{~W}$ & 400 & 21.8 & 7.1 & 45 \\
\hline Queensland (Australia) & QLD & Paluma Range National Park & $18.98 \mathrm{~S}$ & $146.17 \mathrm{E}$ & 800 & 15.5 & 6.1 & 37 \\
\hline Trinidad & TRN & Northern Range & $10.69 \mathrm{~N}$ & $62.29 \mathrm{~W}$ & 170 & 24.7 & 8.2 & 380 \\
\hline Venezuela & VNZ & Sierra de Perijá & $11.13 \mathrm{~N}$ & $72.38 \mathrm{~W}$ & 100 & 25.5 & 8.3 & 378 \\
\hline
\end{tabular}


Table 2. Exponential litter decay rates ( $k$ ) of Alnus glutinosa and native litter in fine- and coarse-mesh bags at each of 14 tropical sites, calculated as a function of thermal sums in degree-days (dd). Means and standard errors (SE) of $k$, sample size (n), and statistics of linear regression analyses (adjusted $r^{2}$ and $p$-value) are shown.

\begin{tabular}{|c|c|c|c|c|c|c|c|}
\hline Site & Litter & Mesh & $-k / \mathrm{dd}$ & SE & $n$ & $r^{2}$ & $p$ \\
\hline BRL & Alnus & Coarse & 0.001071 & 0.00009 & 15 & 0.92 & $<0.0001$ \\
\hline BRL & Alnus & Fine & 0.001068 & 0.00008 & 15 & 0.93 & $<0.0001$ \\
\hline BRL & Native & Coarse & 0.000246 & 0.00003 & 15 & 0.84 & $<0.0001$ \\
\hline BRL & Native & Fine & 0.000238 & 0.00002 & 15 & 0.92 & $<0.0001$ \\
\hline CRA & Alnus & Coarse & 0.001138 & 0.00051 & 7 & 0.46 & 0.0665 \\
\hline CRA & Alnus & Fine & 0.001171 & 0.00042 & 8 & 0.53 & 0.0262 \\
\hline CRA & Native & Coarse & 0.000928 & 0.00015 & 9 & 0.83 & 0.0002 \\
\hline CRA & Native & Fine & 0.000252 & 0.00008 & 9 & 0.56 & 0.0123 \\
\hline ECD & Alnus & Coarse & 0.002442 & 0.00030 & 8 & 0.91 & 0.0001 \\
\hline ECD & Alnus & Fine & 0.000679 & 0.00008 & 9 & 0.9 & $<0.0001$ \\
\hline ECD & Native & Coarse & 0.000288 & 0.00001 & 9 & 0.98 & $<0.0001$ \\
\hline ECD & Native & Fine & 0.000236 & 0.00002 & 9 & 0.92 & $<0.0001$ \\
\hline FGN & Alnus & Coarse & 0.000840 & 0.00011 & 9 & 0.89 & 0.0001 \\
\hline FGN & Alnus & Fine & 0.000760 & 0.00007 & 9 & 0.94 & $<0.0001$ \\
\hline FGN & Native & Coarse & 0.000290 & 0.00002 & 9 & 0.96 & $<0.0001$ \\
\hline FGN & Native & Fine & 0.000260 & 0.00002 & 9 & 0.96 & $<0.0001$ \\
\hline HKN & Alnus & Coarse & 0.003396 & 0.00055 & 9 & 0.82 & 0.0003 \\
\hline HKN & Alnus & Fine & 0.000736 & 0.00003 & 9 & 0.99 & $<0.0001$ \\
\hline HKN & Native & Coarse & 0.001704 & 0.00021 & 9 & 0.89 & $<0.0001$ \\
\hline HKN & Native & Fine & 0.000749 & 0.00006 & 9 & 0.95 & $<0.0001$ \\
\hline IND & Alnus & Coarse & 0.001493 & 0.00007 & 9 & 0.98 & $<0.0001$ \\
\hline IND & Alnus & Fine & 0.000382 & 0.00002 & 9 & 0.97 & $<0.0001$ \\
\hline IND & Native & Coarse & 0.002446 & 0.00016 & 9 & 0.97 & $<0.0001$ \\
\hline IND & Native & Fine & 0.000616 & 0.00003 & 9 & 0.98 & $<0.0001$ \\
\hline KEN & Alnus & Coarse & 0.000893 & 0.00011 & 9 & 0.89 & $<0.0001$ \\
\hline KEN & Alnus & Fine & 0.000509 & 0.00006 & 9 & 0.91 & $<0.0001$ \\
\hline KEN & Native & Coarse & 0.001297 & 0.00007 & 3 & 0.99 & 0.0027 \\
\hline KEN & Native & Fine & 0.000470 & 0.00013 & 3 & 0.87 & 0.0683 \\
\hline MLY & Alnus & Coarse & 0.001943 & 0.00016 & 15 & 0.91 & $<0.0001$ \\
\hline MLY & Alnus & Fine & 0.000583 & 0.00007 & 15 & 0.83 & $<0.0001$ \\
\hline MLY & Native & Coarse & 0.000649 & 0.00009 & 15 & 0.77 & $<0.0001$ \\
\hline MLY & Native & Fine & 0.000326 & 0.00006 & 15 & 0.66 & 0.0001 \\
\hline MEX & Alnus & Coarse & 0.003843 & 0.00074 & 6 & 0.85 & 0.0034 \\
\hline MEX & Alnus & Fine & 0.001967 & 0.00018 & 6 & 0.96 & 0.0001 \\
\hline MEX & Native & Coarse & 0.002852 & 0.00070 & 6 & 0.77 & 0.0096 \\
\hline MEX & Native & Fine & 0.002385 & 0.00028 & 6 & 0.93 & 0.0004 \\
\hline PAN & Alnus & Coarse & 0.002099 & 0.00026 & 9 & 0.89 & $<0.0001$ \\
\hline PAN & Alnus & Fine & 0.001699 & 0.00023 & 8 & 0.89 & 0.0002 \\
\hline PAN & Native & Coarse & 0.002032 & 0.00011 & 8 & 0.98 & $<0.0001$ \\
\hline PAN & Native & Fine & 0.002162 & 0.00022 & 8 & 0.93 & $<0.0001$ \\
\hline PRC & Alnus & Coarse & 0.006297 & 0.00024 & 5 & 0.99 & $<0.0001$ \\
\hline PRC & Alnus & Fine & 0.004122 & 0.00029 & 8 & 0.97 & $<0.0001$ \\
\hline PRC & Native & Coarse & 0.000960 & 0.00019 & 8 & 0.79 & 0.0014 \\
\hline PRC & Native & Fine & 0.000445 & 0.00003 & 8 & 0.96 & $<0.0001$ \\
\hline QLD & Alnus & Coarse & 0.004540 & 0.00018 & 7 & 0.99 & $<0.0001$ \\
\hline QLD & Alnus & Fine & 0.001123 & 0.00011 & 9 & 0.92 & $<0.0001$ \\
\hline
\end{tabular}


Table 2 (Continued)

\begin{tabular}{|c|c|c|c|c|c|c|c|}
\hline Site & Litter & Mesh & $-k / \mathrm{dd}$ & $\mathrm{SE}$ & $n$ & $r^{2}$ & $p$ \\
\hline QLD & Native & Coarse & 0.000761 & 0.00005 & 9 & 0.97 & $<0.0001$ \\
\hline QLD & Native & Fine & 0.000467 & 0.00003 & 9 & 0.96 & $<0.0001$ \\
\hline TRN & Alnus & Coarse & 0.006100 & 0.00071 & 3 & 0.97 & 0.0134 \\
\hline TRN & Alnus & Fine & 0.002405 & 0.00012 & 7 & 0.99 & $<0.0001$ \\
\hline TRN & Native & Coarse & 0.002033 & 0.00035 & 8 & 0.83 & 0.0007 \\
\hline TRN & Native & Fine & 0.000565 & 0.00004 & 8 & 0.96 & $<0.0001$ \\
\hline VNZ & Native & Coarse & 0.001263 & 0.00007 & 9 & 0.98 & $<0.0001$ \\
\hline VNZ & Native & Fine & 0.000988 & 0.00011 & 9 & 0.91 & $<0.0001$ \\
\hline
\end{tabular}

and across geographic areas and sites (nested within geographic area), with thermal sums (degree days) as the covariate. Because variances of the different groups were not homogeneous, we used permutational analysis of variance (PERMANOVA; version 6.1.12; Primer, Plymouth, UK; Anderson et al. 2008), which makes no assumptions about data distribution, followed by permutational pairwise tests with 999 permutations. We used one model that grouped sites in 3 geographic areas (Central America, South America, and Australasia; excluding Kenya, which was the only African site), and a $2^{\text {nd }}$ model that grouped sites in 2 geographic areas (America and Other). Venezuela was excluded from both models because we did not have data for native litter.

We calculated the ratio between $k$-values in coarseand fine-mesh bags $\left(k_{\mathrm{c}} / k_{\mathrm{f}}\right)$ separately for alder and native litter at each site and used it as an additional measure to assess the contribution of detritivores to litter breakdown (Gessner and Chauvet 2002, Jinggut et al. 2012). We calculated the ratio between alder and native $k$ values $\left(k_{\mathrm{a}} / k_{\mathrm{n}}\right)$, separately for fine- and coarse-mesh bags, to assess the role of local litter types in determining microbial and total breakdown rates at each site. We examined the potential influence of stream elevation and environmental characteristics (temperature, $\mathrm{pH}$, and conductivity) on litter breakdown with multiple regression analyses for each mesh and litter type.

Last, we compared variability in the breakdown rate of Alnus glutinosa litter across our tropical sites with those reported in various large-scale studies of litter breakdown across European regions (Hladyz et al. 2010, Pozo et al. 2011, Woodward et al. 2012) or using litter collected in various European regions (Lecerf and Chauvet 2008). We compared variability between European and tropical regions using $k$ values calculated by regressing litter dry mass remaining against the elapsed time in days $(k / d)$ or against degree days $(k / \mathrm{dd})$, depending on which $k$ values were reported in each study. For consistency with our study, we chose a single stream or observation per region, selected for its low nutrient concentration (Pozo et al. 2011, Woodward et al. 2012), its wooded environment
(Hladyz et al. 2010), or randomly for different seasons/ years and with the densest vegetation (Lecerf and Chauvet 2008). We first quantified variability using the coefficient of variation $(100 \times$ standard deviation $[S D] /$ mean $)$ within tropical or temperate zones, but these were single values that could not be compared statistically. Therefore, we used the Levene's test of homogeneity of variances to compare variability between tropical and temperate sites.

\section{RESULTS}

In most cases the exponential decay model was a fair approximation of the litter breakdown process over 2 mo, although variation among sites and between alder and native litter was high (Table 2, Figs 2, 3). Variability of $k$ values was higher for alder than for native litter in coarsemesh bags $\left(F_{1,25}=10.65, p=0.003\right)$, with no differences between litter types for fine-mesh bags $\left(F_{1,25}=1.81, p=\right.$ $0.19)$. Variability was higher in coarse- than in fine-mesh bags for alder $\left(F_{1,24}=1.24, p=0.020\right)$ but not for native litter $\left(F_{1,26}=1.20, p=0.28\right)$. Litter breakdown did not vary across geographic areas within the tropics in any model (Table S2), so we used a simpler model excluding the factor 'geographic' area that we present as main results. Litter breakdown varied with mesh size and litter type and across tropical sites, with most interactions significant (Table 3). Breakdown of alder litter was faster than native litter, and it was faster in coarse- than in fine-mesh bags for alder litter, but not for native litter (Figs 2, 3).

Ratios of $k$ indicated that litter decomposed faster in coarse- than in fine-mesh bags in most streams, but not all (Table 4). Alder litter lost mass 2 to $5 \times$ faster in coarse than in fine-mesh bags in Hong Kong, Queensland, India, Ecuador, Malaysia, Trinidad, and Mexico, results suggesting that detritivores were important breakdown agents at these sites. In contrast, alder leaves in both types of bags lost mass at similar rates in Brazil, Costa Rica, and French Guiana, indicating that the role of detritivores as litter consumers was negligible. Breakdown rates of native litter in fine- vs coarse-mesh bags also differed among sites. Rates were 2 to $4 \times$ higher in coarse- than in fine-mesh bags in India, Costa Rica, Trinidad, Kenya, Hong Kong, 
Puerto Rico, and Malaysia, whereas rates in the 2 types of bags were similar in French Guiana, Brazil, and Panama.

The $k$ ratios showed that alder litter generally lost mass faster than native litter in both coarse- and fine-mesh bags (Table 4). In coarse-mesh bags, the difference was particularly high (4-9× faster breakdown of alder) in Ecuador, Puerto Rico, Queensland, and Brazil, whereas rates were similar for both types of litter in Panama, and native litter decomposed slightly faster than alder in India and Kenya. In fine-mesh bags, the difference also was substantial (4$9 \times$ faster in alder) in Puerto Rico, Costa Rica, Brazil, and Trinidad, whereas rates were similar for both types of litter in Hong Kong and Kenya, and native litter decomposed slightly faster than alder in India, Mexico, and Panama. Breakdown rates of alder and native litter were not correlated, nor were the $k_{\mathrm{c}} / k_{\mathrm{f}}$ ratios of alder and native litter $(p>0.18$ in all cases).

Multiple regression analyses indicated that stream elevation and the environmental variables were not related to $k$ values (alder litter, coarse mesh: $r^{2}=0.14, F_{4,7}=0.29, p=$ 0.29; alder litter, fine mesh: $r^{2}=0.05, F_{4,7}=0.10, p=0.10$; native litter, coarse mesh: $r^{2}=0.58, F_{4,8}=2.72, p=0.11$; native litter, fine mesh: $r^{2}=0.29, F_{4,8}=0.80, p=0.56$ ).

Variability of alder litter breakdown across tropical streams was higher for $k / d(C V=99 \%$ for coarse-mesh and $86 \%$ for fine-mesh bags) than for $k / \mathrm{dd}(\mathrm{CV}=71$ and $81 \%)$. Variability of $k / d$ in temperate studies ranged from 11 to $73 \%$ in coarse-mesh bags and from 28 to $63 \%$ in finemesh bags, and variability of $k / \mathrm{dd}$ varied from 46 to $61 \%$ in coarse-mesh bags and was $82 \%$ for fine-mesh bags. These values seemed to imply that variability was higher in the tropics, but results of Levene tests were inconsistent (Fig. 4A, B). Variability of $k / d$ did not differ between tropical and temperate studies in any case $(p>0.22$ in all cases; both coarse- and fine-mesh bags). Variability of $k / d d$ in our study did not differ from that reported by Woodward et al. (2012) $\left(F_{1,21}=3.03, p=0.096\right)$ but was lower than that reported by Pozo et al. (2011) for coarse-mesh bags

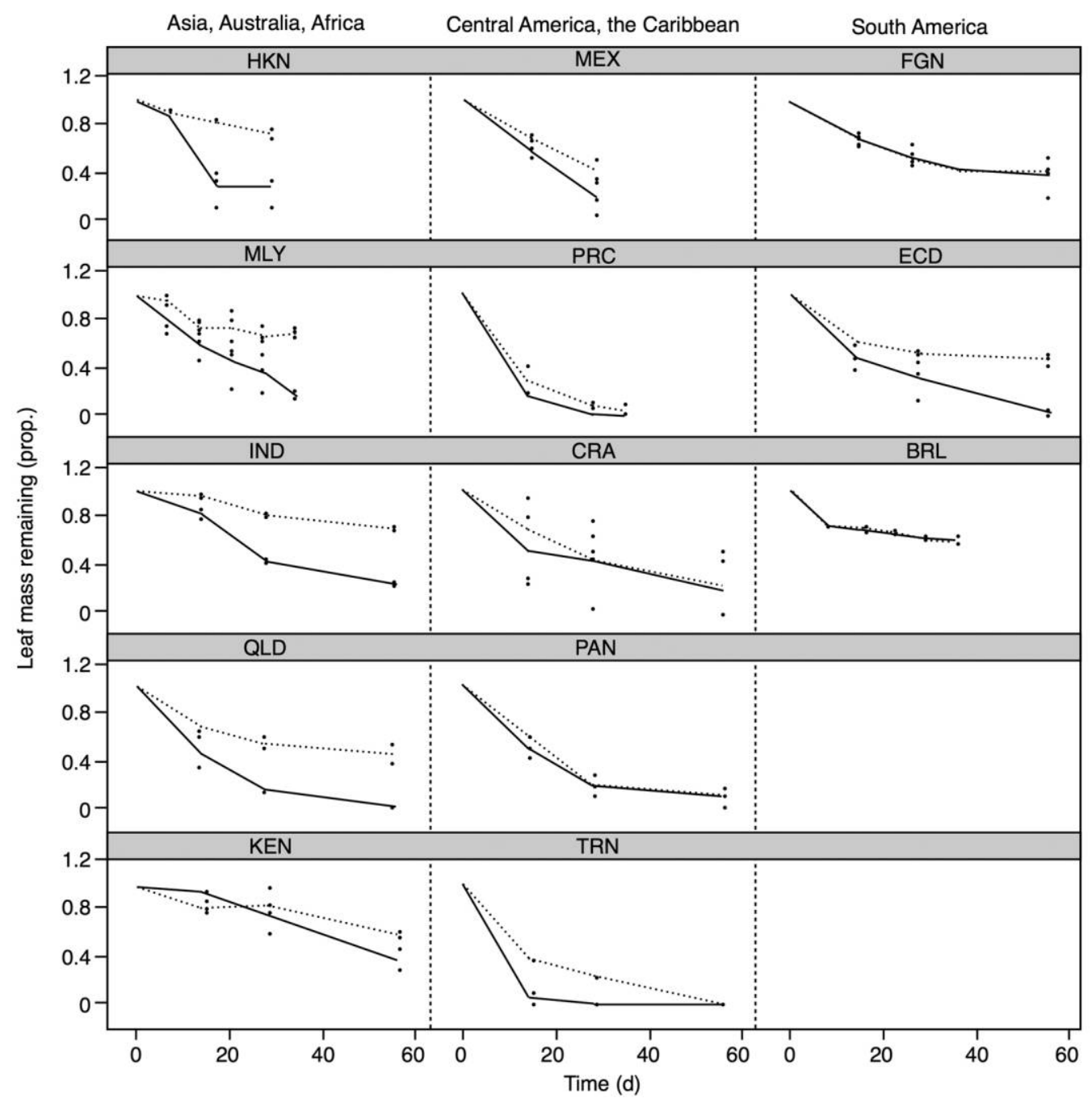

Figure 2. Mass-loss trajectories of alder litter at 13 tropical sites grouped by geographic area. Solid and dotted lines represent litter dry mass remaining in coarse- and fine-mesh bags, respectively. Prop. = proportion. 


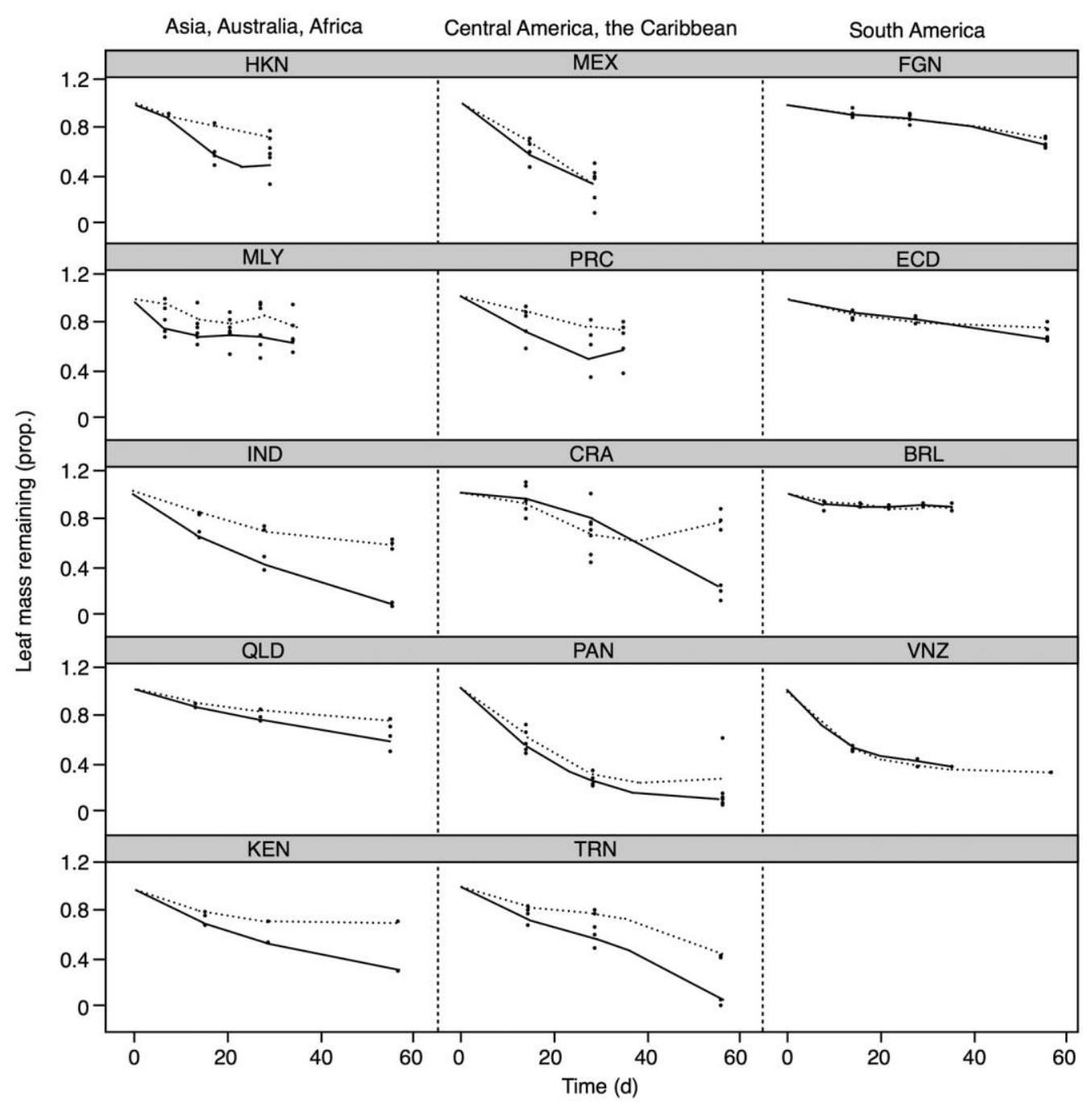

Figure 3. Mass-loss trajectories of native litter mixtures at 14 tropical sites, grouped by geographic area. Solid and dotted lines represent dry mass remaining in coarse- and fine-mesh bags, respectively. Prop. $=$ proportion.

$\left(F_{1,15}=4.70, p=0.047\right)$, and was lower than that reported by Woodward et al. (2012) for fine-mesh bags $\left(F_{1,21}=\right.$ $18.84, p=0.002)$.

\section{DISCUSSION}

Our standardized, temperature-corrected data from comparable near-natural forest streams of different geographic areas showed that litter breakdown rates and the contribution of detritivores to litter breakdown vary greatly within the tropics and between litter types. Litter breakdown was faster and more variable in coarse- than fine-mesh bags, a result indicating that detritivores had a significant role in litter breakdown, but their importance varied from site to site. Moreover, the difference between coarse- and fine-mesh bags and the higher variability in coarse-mesh bags was significant for alder but not for native litter. Most sites had $k_{\mathrm{c}} / k_{\mathrm{f}}$ ratios $>1$, results suggesting that detritivores played a role in litter breakdown, but litter breakdown by detritivores seemed to be negligi- ble at several sites in South or Central America (Brazil, French Guiana, Costa Rica, and Panama).

Alder litter generally broke down faster than native litter in coarse-mesh bags, which could be accessed by invertebrates, and in fine-mesh bags from which macroinvertebrates were absent. This pattern was particularly evident at several American sites, and it suggests that invertebrates or microorganisms were able to exploit alder leaves more effectively than native leaves, indicating greater recalcitrance of the selected native leaves. We found that breakdown rates of alder were more variable than those of native litter in coarse-mesh bags, but we had expected higher variation in recalcitrance of native litter mixtures because the selected riparian species necessarily varied from site to site. This unexpected result may reflect different abilities of detritivores to break down alder at different sites, compared to more similar (and generally lower) abilities to break down native litter, or it may be the result of differences in detritivore colonization of alder litter 
Table 3. Results of permutational analysis of variance testing for differences in $\ln$ (proportion of litter dry mass remaining) in coarse- and fine-mesh bags, litter type (Alnus vs native), and across sites, with thermal sums (degree days) used as a covariate. Degrees of freedom (df), sums of squares (SS), the test statistic (pseudo- $F$ ), and $p$-values resulting from 999 permutations are shown.

\begin{tabular}{lrrrc}
\hline \multicolumn{1}{c}{ Source of variation } & \multicolumn{1}{c}{ df } & \multicolumn{1}{c}{ SS } & Pseudo- $F$ & $p$ \\
\hline Mesh & 1 & 35.18 & 63.28 & 0.001 \\
Litter & 1 & 53.05 & 95.42 & 0.001 \\
Mesh $\times$ litter & 1 & 9.50 & 17.08 & 0.001 \\
Site $($ within geographic area $)$ & 12 & 192.34 & 28.83 & 0.001 \\
Mesh $\times$ site & 12 & 72.40 & 10.85 & 0.001 \\
Litter $\times$ site & 12 & 142.04 & 21.29 & 0.001 \\
Mesh $\times$ litter $\times$ site & 12 & 63.83 & 9.57 & 0.001 \\
Degree days & 1 & 0.02 & 0.03 & 0.875 \\
Mesh $\times$ degree days & 1 & 0.07 & 0.13 & 0.728 \\
Litter $\times$ degree days & 1 & 2.06 & 3.71 & 0.068 \\
Mesh $\times$ litter $\times$ degree days & 1 & 2.08 & 3.74 & 0.070 \\
Site $\times$ degree days & 12 & 15.62 & 2.34 & 0.038 \\
Mesh $\times$ site $\times$ degree days & 12 & 13.01 & 1.95 & 0.066 \\
Litter $\times$ site $\times$ degree days & 12 & 43.32 & 6.49 & 0.001 \\
Mesh $\times$ litter $\times$ site $\times$ degree days & 11 & 17.69 & 2.89 & 0.010 \\
Error & 368 & 204.60 & & \\
\hline
\end{tabular}

across sites. At several sites, native leaves were broken down at rates greater than or similar to those measured for alder, suggesting that some native species were more palatable than alder or that detritivores were less able to cope with exotic than with native litter, as has been found for some invertebrate species elsewhere (Boyero et al. 2012a). However, native litter also broke down faster than alder in fine-mesh bags at some of these sites, so other factors, such as stream characteristics, litter quality, or microbial assemblage composition also might play a role

Table 4. Ratio between litter breakdown rates in coarse- and fine-mesh bags $\left(k_{\mathrm{c}} / k_{\mathrm{f}}\right)$, indicating the contribution of detritivores to breakdown for each site and type of litter, and ratio between litter breakdown rates in alder and native litter $\left(k_{\mathrm{a}} / k_{\mathrm{n}}\right)$, indicating the effect of litter type on total and microbial breakdown rates (coarse- and fine-mesh bags, respectively). - indicates data not available.

\begin{tabular}{lcccc}
\hline Study site & $\begin{array}{c}k_{\mathrm{c}} / k_{\mathrm{f}} \\
(\text { alder }\end{array}$ & $\begin{array}{c}k_{\mathrm{c}} / k_{\mathrm{f}} \\
(\text { native }\end{array}$ & $\begin{array}{c}k_{\mathrm{a}} / k_{\mathrm{n}} \\
\text { (coarse mesh) }\end{array}$ & $\begin{array}{c}k_{\mathrm{a}} / k_{\mathrm{n}} \\
(\text { fine mesh) }\end{array}$ \\
\hline BRL & 1.00 & 1.03 & 4.35 & 4.49 \\
CRA & 0.97 & 3.68 & 1.23 & 4.65 \\
ECD & 3.59 & 1.22 & 8.48 & 2.88 \\
FGN & 1.11 & 1.12 & 2.90 & 2.92 \\
HKN & 4.61 & 2.28 & 1.99 & 0.98 \\
IND & 3.91 & 3.97 & 0.61 & 0.62 \\
KEN & 1.75 & 2.76 & 0.69 & 1.08 \\
MLY & 3.33 & 1.99 & 2.99 & 1.79 \\
MEX & 1.95 & 1.20 & 1.35 & 0.82 \\
PAN & 1.24 & 0.94 & 1.03 & 0.79 \\
PRC & 1.53 & 2.16 & 6.56 & 9.26 \\
QLD & 4.04 & 1.63 & 5.96 & 2.40 \\
TRN & 2.54 & 3.60 & 3.00 & 4.26 \\
VNZ & - & 1.28 & - & - \\
\hline
\end{tabular}



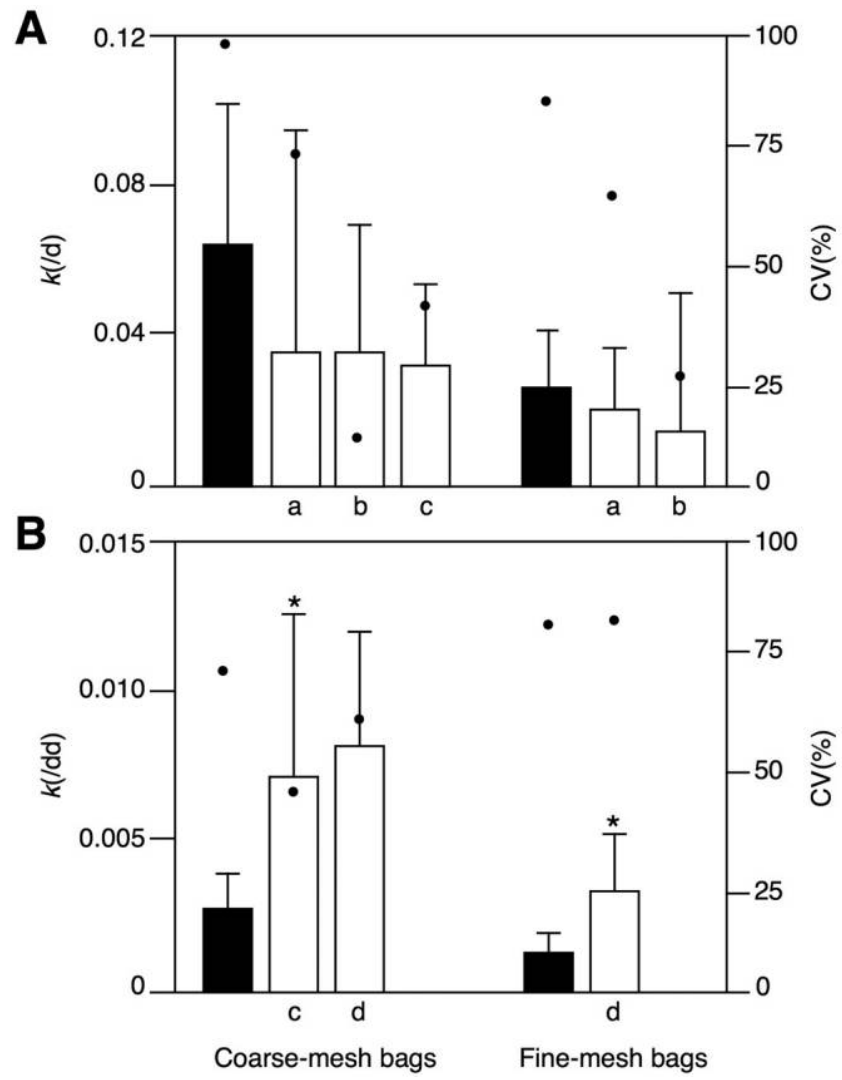

Figure 4. Mean (+ 95\% confidence interval) exponential decay rates $(k)$ for Alnus glutinosa calculated by regressing ln (proportion of litter dry mass remaining) against elapsed time in days $(k / d)(A)$ or degree days $(k / d d)(B)$ in our study at 13 tropical sites and in 4 large-scale studies conducted in temperate regions. $\mathrm{a}=$ Lecerf and Chauvet (2008), $\mathrm{b}=$ Hladyz et al (2010), c = Pozo et al. (2011), d = Woodward et al. (2012).

* indicates significant differences in the variability of $k$ values between our tropical and a particular temperate study as indicated by Levene tests of homogeneity of variances. Dots represent coefficients of variation for $k$ values in each study.

(cf. Bruder et al. 2014). No differences in breakdown could be attributed to elevation or water-quality characteristics, and other environmental differences are unlikely to play a notable role because we selected sites for their similar characteristics. More detailed information on microbial and detritivore assemblage composition at each site would facilitate further exploration of the potential sources of variation in breakdown of alder vs native litter.

Comparison of our data on alder litter breakdown with European data provided no evidence that variability was higher within than outside the tropics. The number and diversity of detritivores are more variable across tropical than across temperate streams (Boyero et al. 2011a), a pattern suggesting that the role of detritivores in litter breakdown also could be more variable within the tropics. Variability in detritivore numbers (and, potentially, litter breakdown rate) also is high within single tropical areas, as shown in studies in the Colombian Andes (Mathuriau and Chauvet 2002, Chará-Serna et al. 2012) and Kenya (Dobson et al. 2002, Masese et al. 2014). These results suggest that future investigators should consider the extent of variability of litter breakdown patterns at multiple spatial and temporal scales (see also Royer and Minshall 2003, Tiegs et al. 2009), if we are to understand the factors that control this process in tropical streams.

What differences among forested streams might cause high variability in litter breakdown? First, the high species diversity and taxonomic variability of tropical riparian forests and their litter inputs (Benson and Pearson 1993, Wright 2002, Bastian et al. 2007) might increase variability, but our results show that breakdown of alder was more variable than that of native litter mixtures. Second, fluctuations in flow might produce the apparent variability in litter breakdown, and unpredictably flashy streams, such as many in the tropics (e.g., Yule and Pearson 1996, Dudgeon 2000), might have more spatially and temporally variable detritivore assemblages than streams with more predictable flows, which are more common in temperate and boreal zones (e.g., Giberson and Hall 1988; but see Winterbourne et al. 1981). However, we do not have suitable data on antecedent flows to test this hypothesis, and at least some of the European data challenge this suggestion. We are currently unable to fully explain the high variability in litter breakdown, partly because variability in microbial and detritivore assemblages between and within regions remains insufficiently understood. Despite increasing numbers of case studies and several recent global comparisons (e.g., Boyero et al. 2011b), more systematic research is needed if we are to develop a general understanding of litter breakdown across geographic regions and develop litterbreakdown models for tropical streams to match those of temperate streams (cf. Woodward et al. 2012).

\section{ACKNOWLEDGEMENTS}

We thank the numerous assistants who helped with field and laboratory work across the globe. Field work was funded by a grant from the National Geographic Society's Committee for Research and Exploration (grant number 7980-06) to LB.

\section{LITERATURE CITED}

Anderson, M. J., R. N. Gorley, and K. R. Clarke 2008. PERMANOVA+ for PRIMER: guide to software and statistical methods. PRIMER-E, Plymouth, UK.

Bastian, M., L. Boyero, B. R. Jackes, and R. G. Pearson. 2007. Leaf litter diversity and shredder preferences in an Australian tropical rain-forest stream. Journal of Tropical Ecology 23:219-229.

Benson, L., and R. G. Pearson. 1993. Litter inputs to a tropical Australian rainforest stream. Australian Journal of Ecology 18:377-383.

Boyero, L., L. A. Barmuta, L. Ratnarajah, K. Schmidt, and R. G. Pearson. 2012a. Effects of exotic riparian vegetation on leaf breakdown by shredders: a tropical-temperate comparison. Freshwater Science 31:296-303. 
Boyero, L., R. G. Pearson, D. Dudgeon, V. Ferreira, M. A. S. Graça, M. O. Gessner, A. J. Boulton, E. Chauvet, C. M. Yule, R. J. Albariño, A. Ramírez, J. E. Helson, M. Callisto, M. Arunachalam, J. Chará, R. Figueroa, J. M. Mathooko, J. F. Gonçalves, M. S. Moretti, A. M. Chará-Serna, J. N. Davies, A. Encalada, S. Lamothe, L. M. Buria, J. Castela, A. Cornejo, A. O. Y. Li, C. M’Erimba, V. D. Villanueva, M. C. Zúñiga, C. M. Swan, and L. A. Barmuta. 2012b. Global patterns of stream detritivore distribution: implications for biodiversity loss in changing climates. Global Ecology and Biogeography 21:134-141.

Boyero, L., R. G. Pearson, D. Dudgeon, M. A. S. Graça, M. O. Gessner, R. J. Albariño, V. Ferreira, C. M. Yule, A. J. Boulton, M. Arunachalam, M. Callisto, E. Chauvet, A. Ramírez, J. Chará, M. S. Moretti, J. F. Gonçalves, J. E. Helson, A. M. CharáSerna, A. C. Encalada, J. N. Davies, S. Lamothe, A. Cornejo, A. O. Y. Li, L. M. Buria, V. D. Villanueva, M. C. Zúñiga, and C. M. Pringle. 2011a. Global distribution of a key trophic guild contrasts with common latitudinal diversity patterns. Ecology 92:1839-1848.

Boyero, L., R. G. Pearson, M. O. Gessner, L. A. Barmuta, V. Ferreira, M. A. S. Graça, D. Dudgeon, A. J. Boulton, M. Callisto, E. Chauvet, J. E. Helson, A. Bruder, R. J. Albariño, C. M. Yule, M. Arunachalam, J. N. Davies, R. Figueroa, A. S. Flecker, A. Ramírez, R. G. Death, T. Iwata, J. M. Mathooko, C. Mathuriau, J. F. Gonçalves, M. Moretti, T. Jinggut, S. Lamothe, C. M'Erimba, L. Ratnarajah, M. H. Schindler, J. Castela, L. M. Buria, A. Cornejo, V. D. Villanueva, and D. C. West. 2011b. A global experiment suggests climate warming will not accelerate litter decomposition in streams but may reduce carbon sequestration. Ecology Letters 14:289-294.

Boyero, L., A. Ramírez, D. Dudgeon, and R. G. Pearson. 2009. Are tropical streams really different? Journal of the North American Benthological Society 28:397-403.

Bruder, A., M. H. Schindler, M. S. Moretti, and M. O. Gessner. 2014. Litter decomposition in a temperate and a tropical stream: the effects of species mixing, litter quality and shredders. Freshwater Biology 59:438-449.

Camacho, R., L. Boyero, A. Cornejo, A. Ibáñez, and R. G. Pearson. 2009. Local variation in shredder distribution can explain their oversight in tropical streams. Biotropica 41:625-632.

Chará-Serna, A. M., J. D. Chará, M. D. C. Zúñiga, R. G. Pearson, and L. Boyero. 2012. Diets of leaf litter-associated invertebrates in three tropical streams. International Journal of Limnology 48:139-144.

Cheshire, K., L. Boyero, and R. G. Pearson. 2005. Food webs in tropical Australian streams: shredders are not scarce. Freshwater Biology 50:748-769.

Cummins, K. W., and M. J. Klug. 1979. Feeding ecology of stream invertebrates. Annual Review of Ecology and Systematics 10:147-172.

Dobson, M., A. Magana, J. M. Mathooko, and F. K. Ndegwa. 2002. Detritivores in Kenyan highland streams: more evidence for the paucity of shredders in the tropics? Freshwater Biology 47:909-919.

Dudgeon, D. 2000. The ecology of tropical Asian rivers and streams in relation to biodiversity conservation. Annual Review of Ecology and Systematics 31:239-263.

Dudgeon, D., and K. K. Y. Wu. 1999. Leaf litter in a tropical stream: food or substrate for macroinvertebrates? Archiv für Hydrobiologie 146:65-82.
Gessner, M. O., and E. Chauvet. 2002. A case for using litter breakdown to assess functional stream integrity. Ecological Applications 12:498-510.

Gessner, M. O., E. Chauvet, and M. Dobson. 1999. A perspective on leaf litter breakdown in streams. Oikos 85:377-384.

Giberson, D. J., and R. J. Hall. 1988. Seasonal variation in faunal distribution within the sediments of a Canadian Shield stream, with emphasis on responses to spring floods. Canadian Journal of Fisheries and Aquatic Sciences 45:1994-2002.

Graça, M. A. S., C. Cressa, M. O. Gessner, M. J. Feio, K. A. Callies, and C. Barrios. 2001. Food quality, feeding preferences, survival and growth of shredders from temperate and tropical streams. Freshwater Biology 46:947-957.

Hill, W. R., M. G. Ryon, and E. M. Schilling. 1995. Light limitation in a stream ecosystem: responses by primary producers and consumers. Ecology 76:1297-1309.

Hladyz, S., S. D. Tiegs, M. O. Gessner, P. S. Giller, G. Risnoveanu, E. Preda, M. Nistorescu, M. Schindler, and G. Woodward. 2010. Leaf-litter breakdown in pasture and deciduous wood land streams: a comparison among three European regions. Freshwater Biology 55:1916-1929.

Irons, J. G., M. W. Oswood, R. J. Stout, and C. M. Pringle. 1994. Latitudinal patterns in leaf litter breakdown: is temperature really important? Freshwater Biology 32:401-411.

Jinggut, T., C. M. Yule, and L. Boyero. 2012. Stream ecosystem integrity is impaired by logging and shifting agriculture in a global megadiversity center (Sarawak, Borneo). Science of the Total Environment 437:83-90.

Julian, J. P., S. Z. Seegert, S. M. Powers, E. H. Stanley, and M. W. Doyle. 2011. Light as a first-order control on ecosystem structure in a temperate stream. Ecohydrology 4:422432.

Lecerf, A., and E. Chauvet. 2008. Intraspecific variability in leaf traits strongly affects alder leaf decomposition in a stream. Basic and Applied Ecology 9:598-605.

Masese, F. O., N. Kitaka, J. Kipkemboi, G. M. Gettel, K. Irvine, and M. E. McClain. 2014. Macroinvertebrate functional feeding groups in Kenyan highland streams: evidence for a diverse shredder guild. Freshwater Science 33:435-450.

Mathuriau, C., and E. Chauvet. 2002. Breakdown of leaf litter in a Neotropical stream. Journal of the North American Benthological Society 21:384-396.

Pozo, J., J. Casas, M. Menéndez, S. Mollá, I. Arostegui, A. Basaguren, C. Casado, E. Descals, J. García-Avilés, J. M. González, A. Larrañaga, E. López, M. Lusi, O. Moya, J. Pérez, T. Riera, N. Roblas, and M. J. Salinas. 2011. Leaf-litter decomposition in headwater streams: a comparison of the process among four climatic regions. Journal of the North American Benthological Society 30:935-950.

Royer, T. V., and G. W. Minshall. 2003. Controls on leaf processing in streams from spatial-scaling and hierarchical perspectives. Journal of the North American Benthological Society 22:352-358.

Tank, J. L., E. J. Rosi-Marshall, N. A. Griffiths, S. A. Entrekin, and M. L. Stephen. 2010. A review of allochthonous organic matter dynamics and metabolism in streams. Journal of the North American Benthological Society 29:118-146.

Tiegs, S. D., P. O. Akinwole, and M. O. Gessner. 2009. Litter decomposition across multiple spatial scales in stream networks. Oecologia (Berlin) 161:343-351. 
Webster, J. R., and E. F. Benfield. 1986. Vascular plant breakdown in freshwater ecosystems. Annual Review of Ecology and Systematics 17:567-594.

Webster, J. R., J. B. Wallace, and E. F. Benfield. 2006. Organic processes in streams of the eastern United States. Pages 117187 in C. E. Cushing, K. W. Cummins, and G. W. Minshall (editors). River and stream ecosystems of the world. University of California Press, Berkeley, California.

Winterbourne, M. J., J. S. Rounick, and B. Cowie. 1981. Are New Zealand stream ecosystems really different? New Zealand Journal of Marine and Freshwater Research 15:321-328.

Woodward, G., M. O. Gessner, P. S. Giller, V. Gulis, S. Hladyz, A. Lecerf, B. Malmqvist, B. B. McKie, S. D. Tiegs, H. Cariss, M. Dobson, A. Elosegi, V. Ferreira, M. A. S. Graça, T. Fleit- uch, J. O. Lacoursière, M. Nistorescu, J. Pozo, G. Risnoveanu, M. Schindler, A. Vadineanu, L. M. Vought, and E. Chauvet. 2012. Continental-scale effects of nutrient pollution on stream ecosystem functioning. Science 336:1438-1440.

Wright, S. J. 2002. Plant diversity in tropical forests: a review of mechanisms of species coexistence. Oecologia (Berlin)130:1-14.

Yule, C. M., M. Y. Leong, K. C. Liew, L. Ratnarajah, K. Schmidt, H. M. Wong, R. G. Pearson, and L. Boyero. 2009. Shredders in Malaysia: abundance and richness are higher in cool upland tropical streams. Journal of the North American Benthological Society 28:404-415.

Yule, C. M., and R. G. Pearson. 1996. Aseasonality of benthic invertebrates in a tropical stream on Bougainville Island, Papua New Guinea. Archiv für Hydrobiologie 137:95-117. 